\title{
The short and one-year outcome of transcatheter Patent Ductus Arteriosus closure at Inkosi Albert Luthuli Central Hospital, Durban, South Africa: A Descriptive retrospective chart review
}

\section{K. Koolash and E.G.M. Hoosen}

Department of Paediatrics and Child Health, Nelson R. Mandela School of Medicine, Faculty of Health Sciences, University of KwaZulu-Natal, Durban, South Africa

Address for correspondence:

Dr K. Koolash

605 Currie Road

Essenwood

Durban

4001

South Africa

Email:

k.koolash@gmail.com

\section{INTRODUCTION}

During foetal life, the ductus arteriosus is a normal and essential structure that connects the pulmonary artery to the descending aortic arch. Its function is to divert blood away from the pulmonary bed while the foetus is intrauterine.

At delivery, cord clamping, and lung expansion causes a systemic rise in oxygen saturation, pulmonary vasodilatation and a drop in pulmonary vascular resistance, leading to a sudden reversal of flow in the ductus arteriosus from right to left to left to right.

The ductus arteriosus in the foetus is large, with a diameter approximating that of the descending aorta. At birth, the rise in systemic arterial oxygen tension and a decrease in circulating prostaglandin E2 levels (which were being produced by the placenta) trigger ductal constriction, which begins within 10 I 5 hours after delivery. Closure begins from the pulmonary end to the aortic end and is usually complete by 2 - 3 days of age.

Patent ductus arteriosus (PDA) occurs when the ductus arteriosus fails to close spontaneously shortly after birth. It accounts for about $6 \%-11 \%$ of all congenital heart defects.(I) A strong association between prematurity and patent ductus arteriosus has been described. ${ }^{(2,3)}$

A PDA causes a drop in the pulmonary vascular resistance (PVR) resulting in increasing left to right shunting. If the PDA is large, this results in increased pulmonary blood flow and reduced aortic flow. This causes cardiac failure with infants

\section{ABSTRACT}

Background: Transcatheter closure of patent ductus arteriosus is a common intervention worldwide. A review of the outcomes of patients undergoing this procedure was undertaken at a central hospital in Durban, South Africa.

Methods: Retrospective observational descriptive study of the short ( $<$ I year) and long-term ( $>$ I year) efficacy and safety of patients who underwent transcatheter closure of PDA from January 2010 - December 2015 at Inkosi Albert Luthuli Central Hospital (IALCH), Durban, KwaZulu-Natal.

Results: Over the 5 years, 181 patients underwent cardiac catheterisation for PDA closure: 170 (93.9\%) had successful percutaneous closure, and I I (6.07\%) required surgical ligation. Mean age was $30.2 \pm 9.7$ months, weight $11.2 \mathrm{~kg} \pm 3.6 \mathrm{~kg}$, PDA diameter on echocardiography was $3.64 \mathrm{~mm}$ (SD $\pm 0.97 \mathrm{~mm}$ ), fluoroscopy time 13.66 minutes (SD $\pm 4.37 \mathrm{~min}$ ) and radiation dose $468.6 \mathrm{I}$ microGrays (SD $\pm 149.9 \mathrm{microGrays}$ ). Devices used included the Amplatzer Duct Occluder (ADO) I,ADO II, ADO II AS, Cera, Occlutech, detachable coils and vascular plugs.

Twenty-five patients (15\%) had complications (6 major: 2 device embolisation, I blood loss and 3 pulse loss). Conclusion: Percutaneous PDA closure at IALCH, South Africa, had a comparable level of safety and efficacy to reports from other centres. SAHeart 2020;17:70-76

failing to grow adequately, developing respiratory distress, and having feeding difficulties, tachypnoea, tachycardia and hepatomegaly. The degree to which one is affected depends on the size of the PDA, as well as the PVR. Smaller defects may remain relatively asymptomatic, however, there is a significant lifetime risk of repeated chest infections, pulmonary hypertension and infective endocarditis precipitated by endothelial damage caused by the turbulent flow. Closure of the defect is indicated in all children with defects causing any degree of heart failure, as well as those at risk of infective endocarditis. This includes all patients with the typical continuous or "machinery" murmur generated by a PDA.

In 1939, the first successful cardiac surgical procedure, ligation of a PDA, was reported and became a routine procedure shortly thereafter. ${ }^{(4)}$ Transcatheter closure, however, was first described by Portsman, et al. in 1967, with rapid development 
and refinement of devices used occurring over the next 3 decades. ${ }^{(5)}$ Echocardiographic advancement allowed reliable diagnosis of the PDA as well as evaluation of the anatomy and size of the duct by a non-invasive method. The limitations of echocardiography are that it is operator dependent and requires skill and experience. Angiography further assists in delineating size and anatomy with more accuracy. However, it carries the burden of being an invasive procedure, as well as requiring exposure to radiation.

PDA may vary in size and shape. Some are funnel-shaped, others tubular, others with no length at all (aorto-pulmonary window type), while others may have more complex morphology with multiple constrictions. This heterogeneity makes it impossible to use a single device to close every patent ductus arteriosus. Thus, different devices may be required for differing morphologies and sizes of defects.

Krichenko, et al. classified patent ductus arteriosus into 5 different types based on a lateral descending thoracic aortogram. ${ }^{(6)}$ (Figure I). While not universally accepted, the classification may assist in decision-making regarding choice of device as well as expected complications during device placement.
The commonly described complications specific to transcatheter closure of PDA include a residual shunt, left pulmonary artery obstruction, protrusion of device into the aorta, and embolisation of the device. The incidence increases with certain types and size ducts and with the use of certain devices, specifically coils for occlusion. Other complications may be related to cardiac catheterisation in general, and include vessel damage, myocardial perforation and arrhythmias. Anaesthetic complications can also be expected.

The Amplatzer ${ }^{\text {TM }}$ devices first implanted in $1996^{(7)}$ have since been shown to be safe, effective and relatively easy to use with the ability to safely close most types of PDA. ${ }^{(8-19)}$ Similar devices subsequently developed have demonstrated similar outcomes. Prior to the development of the Amplatzer device, detachable coils were the most commonly used device. These were, however, generally only suitable for smaller PDAs with a higher risk of embolisation and residual leaks. In recent years, however, other devices have become available, increasing the range of patients who can be offered closure.

The aim and objective of this study was to assess the immediate and one-year safety and efficacy of percutaneous closure of patent ductus arteriosus in patients presenting to the Paediatric

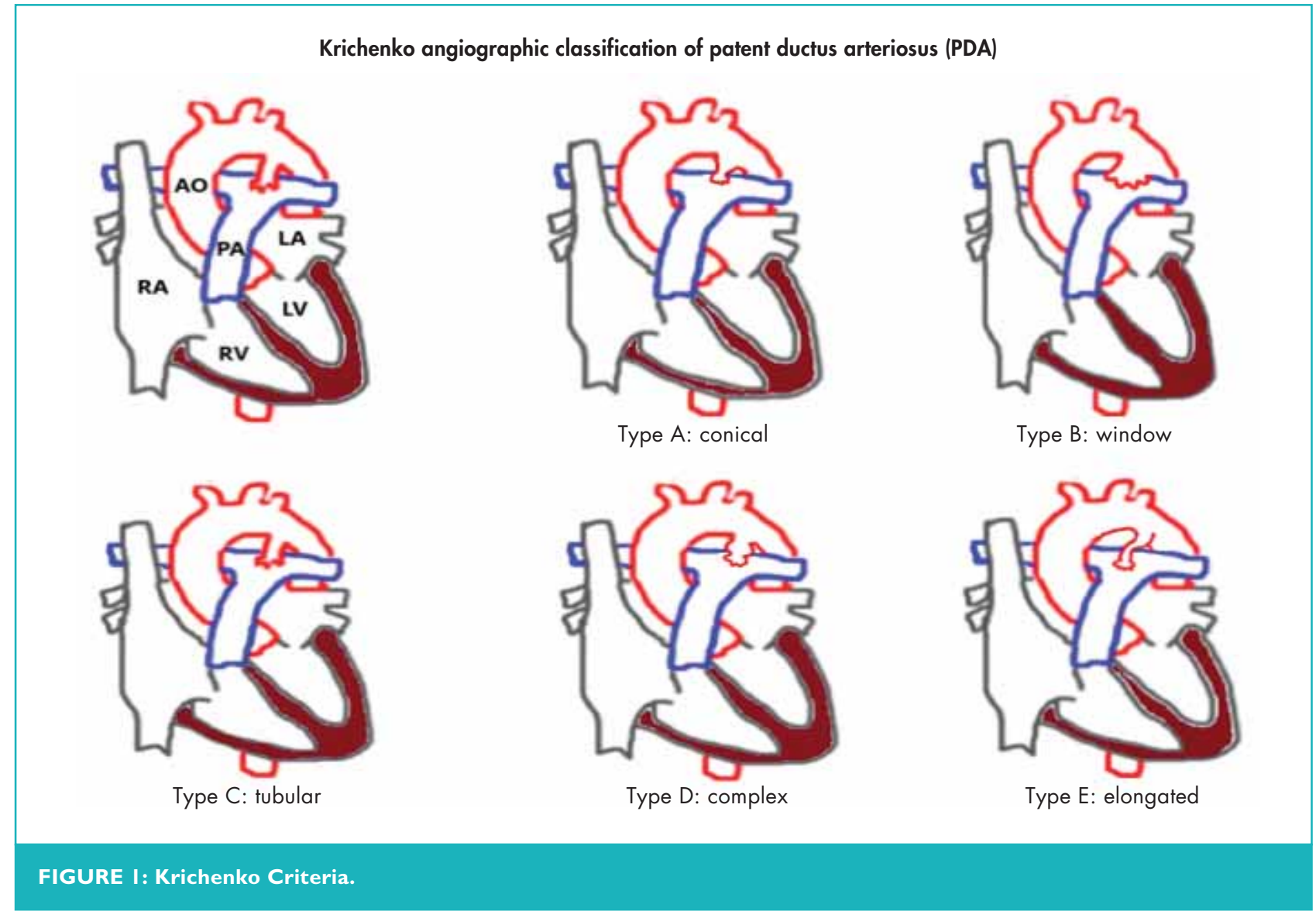


Cardiology Unit at Inkosi Albert Luthuli Central Hospital (IALCH), Durban, South Africa, between January 2010 and December 2015.

The hospital is the only government-run hospital providing paediatric cardiology services in the province. Eighty-five percent of the province's II million population are dependent on public health services. Thirty to 40 transcatheter closures of PDA are performed annually at Inkosi Albert Luthuli Central Hospital presently.

The purpose of this study was to document the patient profile, device use trends, as well as efficacy and safety of transcatheter closure of PDA at this institution.

\section{METHODOLOGY}

\section{Study design \& population}

A descriptive retrospective chart review (using the Meditech electronic database) of all patients who presented to the Paediatric Cardiology Unit at the Inkosi Albert Luthuli Central Hospital, Durban, South Africa, was performed. One hundred and eighty-one of these patients (age 4 months - 372 months) who underwent percutaneous transcatheter closure of their PDA according to the established criteria for occlusion, from January 2010 - December 2015, were retrieved.

Ethics approval was obtained from the Biomedical Research Ethics Committee, Department of Health, and IALCH Medical Manager.

Patients who had surgical closure of PDA without attempted transcatheter closure were excluded from the study.

\section{Data capturing and analysis}

Patient demographics and other variables related to the intervention were captured in a data collection sheet and laid out on an Excel spread sheet for analysis. The variables included age, gender, weight, preterm/term, birth weight, PDA size on echocardiography and angiography, fluoroscopy time and radiation exposure dose (contrast dose was not recorded) and type of device used. Krichenko classification $(A, B, C, D, E)^{(6)}$ was used to record the anatomical type of the patent ductus arteriosus. Angiography post deployment was used to determine the immediate outcome. This was classified as complete closure, small residual leak, large leak or unsuccessful closure requiring surgical ligation. Post-procedure results were documented by echocardiography at I day, 6 weeks, I year and, where applicable, beyond I year at | -year intervals. Complications were divided into major and minor.

Quantitative data were summarised as mean and standard deviation and/or the median and range depending on the frequency distribution. Categorical data were reported as frequencies and percentages.
Major and minor complications were reported by age, gestation, weight and device type and compared using a Chi Square test or Fisher's exact test as appropriate. Efficacy of device closure was compared using a Chi-Square or Fisher's exact test.

Data were analysed using Stata v13 statistical software and a $\mathrm{p}$-value of $<0.05$ was considered statistically significant.

\section{PATENT DUCTUS ARTERIOSUS DEVICE OCCLUSION PROCEDURE}

The presence and size of the PDA was confirmed by physical examination and echocardiography on day of admission and was recorded. Written consent was obtained from the legal guardians/patients for the intervention after fully explaining the procedure.

The patient had either general anaesthesia or sedation with midazolam and ketamine, which were the most common agents used. General anaesthesia was generally reserved for selected patients at risk for upper airway obstruction, such as those with Trisomy 21. General anaesthesia could not be used on every patient due to limitations in the availability of anaesthetic services.

PDA closure method and standard procedure via an arterial or venous access usually via the femoral vessels, was used.(7) The PVR and left to right shunt were usually measured during the procedure. Initially PDA closure was routinely performed with a complete haemodynamic study, however it is now reserved for specific sitiuations. The appropriate device type and size to be used was based on the measurements of the PDA on angiography, which included: the narrowest point, the ampulla, as well as the length and shape of the duct. The size of the device used varied according to the device. For the Amplatzer Occluder, it is normally I mm - $2 \mathrm{~mm}$ larger than the narrowest duct diameter. ${ }^{(20)}$

Pulmonary deployment was used for most patients, while for certain devices and in certain patients, aortic deployment was used. After placement of the device, the correct position was ascertained using angiography and echocardiography. Only then was the device released.

The patients were monitored during and after the procedure. Monitoring was continued in the paediatric ward overnight for complications, including haemorrhage, pulse loss, hypotension or arrhythmias. The patients were then usually discharged the next day after confirming echocardiographically, clinically and radiologically that the device was in the correct position and that the PDA was closed.

Patients were then followed up at 6 weeks and I-year post procedure. Subsequent follow up was only performed in selected patients who had either a residual leak, other asso- 
ciated cardiac abnormalities requiring follow up, or gradients in the aorta or pulmonary arteries that required further follow up or intervention.

\section{RESULTS}

\section{Patient demographics}

One hundred and 81 patients were identified who fulfilled the criteria for inclusion during the 6-year period, January 2010 December 2015. Fifty-two were male (28\%) and 129 were female (72\%). Age range was 4 months - 372 months.

In terms of gestational age at birth, $121 / 181$ (66.8\%) were term deliveries. Pre-term deliveries accounted for 57/181 (31.5\%), while in $3(1.7 \%)$ birth gestational age was not recorded.

\section{Characteristics of patent ductus arteriosus:}

The Krichenko criteria were used to classify the patent ductus arteriosus shapes from $A-E^{(6)}$ (Figure I). Type A predominated, with a total of I 10 (60.8\%), with type $D$ being the least common (Table I).

\section{TABLE I: Types of PDA according to Krichenko criteria.}

\begin{tabular}{|c|c|c|}
\hline Type of PDA & Total & $\begin{array}{l}\text { Successful } \\
\text { closure }\end{array}$ \\
\hline Type A & 110 & 108 \\
\hline Type B & 10 & 8 \\
\hline Type C & 18 & 12 \\
\hline Type D & 7 & 6 \\
\hline Type E & 18 & 18 \\
\hline NA & 18 & 18 \\
\hline
\end{tabular}

$N A=$ not available.

\begin{tabular}{|l|c|}
\hline TABLE II: Types of devices used. & \\
\hline \hline & Devices \\
\hline ADO I & 139 \\
\hline ADO ॥ & 17 \\
\hline ADO II AS & 3 \\
\hline Detachable coils & 5 \\
\hline CERA & 1 \\
\hline Occlutech & 8 \\
\hline Vascular plugs & 4 \\
\hline
\end{tabular}

ADO I (Amplatzer I), ADO || (Amplatzer II), ADO || AS (Amplatzer II additional sizes).
The mean size of the PDAs was $3.64 \mathrm{~mm}$ (SD $\pm 0.97 \mathrm{~mm}$ ), as measured by echocardiography.

\section{Types of devices used}

Amplatzer Device Occluder (ADO) I was the most commonly used device, followed by ADO ॥, ADO ॥ AS, and others namely Cera, Occlutech, vascular plugs and detachable coils (Table II and Table III). The infrequent use of the other devices is attributed to their availability only from 2012 .

\section{Radiation exposure}

In 2010, the fluoroscopy time and radiation dose were not included in the patient record. Of the 162 patients with adequate records, mean fluoroscopy time was 13.66 minutes (SD $\pm 4.37 \mathrm{~min}$ ) and radiation exposure 468.61 microGrays (SD \pm 149.9microGrays). The contrast dose was not recorded.

\section{Patent ductus arteriosus closure rates}

Of the 181 patients, 170 (93.9\%) had successful closure of patent ductus arteriosus. In II patients (6.1\%), closure was not achieved due to either patent ductus arteriosus size or characteristics such as impingement into the aorta or a left pulmonary artery that made it difficult to close percutaneously.

\section{TABLE III: Different types of devices.}

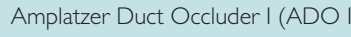

Amplatzer Duct Occluder II (ADO ॥)

Amplatzer Duct Occluder II Additional sizes (ADO II AS )

Cera PDA Occluder

Occlutech PDA Occluder
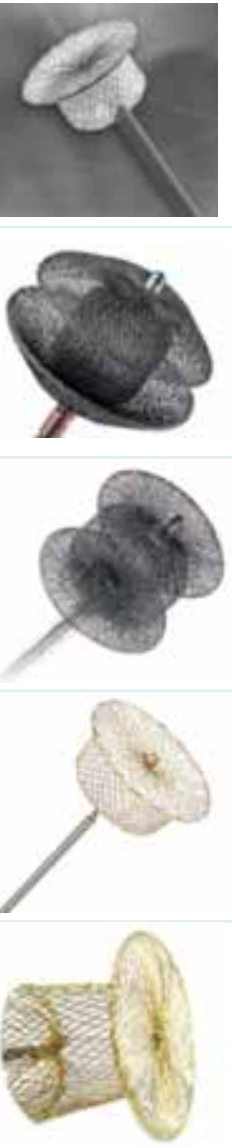
Of those who had successful closure: 130/I70 (76.4\%) had complete closure on day of catheterisation. By day I, $85.3 \%$ had achieved complete closure and by 6 weeks this increased to $94.7 \%$. At I year follow up, $98.2 \%$ had complete closure, while 3 had residual leaks (1.76\%). Patients with complete closure and no further cardiac complications were generally discharged from the clinic at I year.

The 3 patients with residual flow were followed up beyond I year. An Occlutech device was used in two and an ADO I in the other. No further intervention was performed, as the leaks were small with no audible murmur.

\section{Complications}

Twenty-five patients had recorded complications, most of which were classified as minor, the most common being desaturation from sedation requiring manual bagging and/or oxygen administration (Table IV). Six patients had major complications: 2 had device embolisation which were retrieved percutaneously and replaced with an alternative device: I with an ADO I (PDA was then closed with a larger ADO I) and the other with an ADO || AS (an ADO | was then used to close the PDA); I suffered blood loss needing a blood transfusion and 3 had pulse loss, with 2 requiring heparin and I tenecteplase. No mortality from percutaneous transcatheter closure of patent ductus arteriosus was reported in this 5-year period.

Minor complications under "Other" included mild hypotension, mild temperature increases post procedure, and mild intraprocedural upper airway obstruction or hypoventilation requiring bag mask ventilation or oxygen.

\section{Association of complication with various parameters}

Age, weight, gestation and type of device used were compared with the complications encountered in the study. None of the data obtained were statistically significant (Table V), likely due to the small study number.

\begin{tabular}{|c|c|c|}
\hline \multirow[t]{2}{*}{ Major } & Minor & $\mathbf{N}=\mathbf{2 5}$ \\
\hline & PDA spasm & 3 \\
\hline Blood loss requiring transfusion & & । \\
\hline \multirow[t]{2}{*}{ Device embolisation } & & 2 \\
\hline & SVT & । \\
\hline \multirow[t]{2}{*}{ Pulse loss requiring heparin/tenecteplase } & & 3 \\
\hline & Other" & 15 \\
\hline
\end{tabular}

PDA = patent ductus arteriosus, SVT = supraventricular tachycardia.

\section{DISCUSSION}

Transcatheter closure of patent ductus arteriosus is widely used with excellent outcomes. Multiple reports both locally and internationally have shown effectiveness and safety (mean 92\%), with minimal morbidity (mean 23\%). . $8,9,14,18,20)$ Worldwide, the tendency has been, where possible, to favour transcatheter closure over surgical ligation, as it carries less morbidity and mortality. ${ }^{(17,19,21)}$ The patients could be discharged the next day after ascertaining the position of the device by echocardiography.

This 5-year review demonstrated efficacy and safety comparable to reports from other centres

Complications were encountered in 15\% of patients with the majority classified as minor (Table $\mathrm{V}$ ). This is comparable to local as well as international studies (11\% - 23\%). ${ }^{(7,8,9,14,17,20)}$ Sedation-related hypoventilation or airway obstruction requiring manual ventilation and/or oxygen administration was the most frequently encountered, however, these were addressed rapidly with no neurological or other sequelae. There was no death reported during the intervention in our study period. Performing these procedures under general anaesthesia would likely reduce the incidence, however, the availability of general anaesthesia is currently limited at this centre and cannot be offered for all patients undergoing cardiac catheterisation.

Pulse loss as documented in three patients could be avoided by performing the procedure using only venous access. This requires significant reliance on echocardiographic assessment of device position, and is beginning to be implemented in the centre, particularly for smaller patients.

The mean fluoroscopy time measured was 13.66 minutes (SD $\pm 4.37 \mathrm{~min}$ ) and radiation exposure 468.61 microGrays (SD \pm 149.9microGrays). The dose of radiation was not mentioned in other studies, but the duration was comparable or lower than local studies (13-23 minutes), but more when compared to some international studies. ${ }^{(9,18,22)}$ This could be explained by the fact that the hospital is a training centre with trainees generally requiring a longer time for procedures. Complete haemodynamic studies were also routinely performed, initially increasing fluoroscopy time. Contrast dose was not captured.

Current manufacturer recommendations for practically all PDA devices are that they be used in patients older than 6 months and weighing more than 5 kilograms. However, a number of recent studies have demonstrated that device closure can be safely achieved in patients younger than 6 months and weighing even under I kilogram. ${ }^{(23,24)}$ The risk of adverse events was higher in this age group and the benefit of percutaneous closure over surgical ligation needs to be carefully weighed. ${ }^{(17)}$ During the study period, 5 patients were 
TABLE V: Complications according to age/weight/gestational age/device type.

\begin{tabular}{|c|c|c|c|c|}
\hline & Yes & & No & \\
\hline & Number & $\%$ & Number & $\%$ \\
\hline \multicolumn{5}{|c|}{ Age/months $(p$-value $=0.9)$} \\
\hline$\leq 6(6)$ & 0 & 0 & 6 & 100 \\
\hline $6-372(175)$ & 25 & 14.2 & 150 & 85.7 \\
\hline Total (|8|) & 25 & 13.8 & 156 & 86.1 \\
\hline \multicolumn{5}{|c|}{ Weight $/ \mathrm{kg}(\mathrm{p}$-value $=0.4)$} \\
\hline$<5(4)$ & 0 & 0 & 4 & 100 \\
\hline $5.01-54(177)$ & 24 & 13.6 & 153 & 86.4 \\
\hline Total (|8|) & 25 & 13.8 & 156 & 86.1 \\
\hline \multicolumn{5}{|c|}{ Gestation ( $p$-value $=0.1$ ) } \\
\hline Pre-term (57) & 11 & 19.2 & 46 & 80.7 \\
\hline Term (122) & 14 & 11.4 & 108 & 88.5 \\
\hline Not recorded (2) & 0 & 0 & 2 & 100 \\
\hline \multicolumn{5}{|c|}{ Type of device $(\mathrm{p}$-value $=0.7)$} \\
\hline ADO I (I35) & 17 & 12.6 & 117 & 86.7 \\
\hline$A D O \|(17)$ & 3 & 17.6 & 13 & 76.4 \\
\hline Others (29) & 3 & 10.3 & 26 & 89.7 \\
\hline Total (|8|) & 25 & 13.8 & 156 & 86.1 \\
\hline
\end{tabular}

under 6 months of age or under 5 kilograms at the time of the procedure. None had complications. Based on current practice and as further experience with device closure in younger infants is obtained, both nationally and internationally, it is expected that device closure will be increasingly extended to these patients. Female predominance in our cohort is similar to that from other reports. ${ }^{(14)}$

The Amplatzer family of devices were the most commonly used. This was largely due to these devices together with detachable coils, being the only available devices until 20/2. It would be expected that frequency of use of alternative devices would increase with time. Cost differences, suitability for different anatomy, as well as continued availability of various devices, may also play a role in types of device used. A direct comparison of safety and efficacy between devices was not possible in this study.

\section{LIMITATIONS OF THIS STUDY}

The primary limitations of this study were the retrospective nature allowing only previously recorded data to be obtained, as well as the relatively small sample size, as can be expected from a single centre review.

\section{CONCLUSION}

Transcatheter percutaneous closure of patent ductus arteriosus at this centre appeared to be safe, effective and comparable to other reports in the literature. This study adds to the body of literature available on the current status of percutaneous PDA closure both locally and internationally.

\section{Conflict of interest: none declared.}




\section{REFERENCES}

I. Rao PS. Percutaneous closure of patent ductus arteriosus: State of the art. J Invasive Cardiol. 2007;19(7):299-302. https://www.invasivecardiology.com/ article/7465 (accessed 12 March 2019).

2. Kang S, Jivanji S, Mehta C, et al. Outcome after transcatheter occlusion of patent ductus arteriosus in infants less than $6 \mathrm{~kg}$ : A national study from United Kingdom and Ireland. Catheterisation and Cardiovascular Interventions. 20 17;90(7): I | 35- I | 44. https://doi.org/10.1002/ccd.27212.

3. Baspinar O, Sahin DA, Sulu A, et al. Transcatheter closure of patent ductus arteriosus in under $6 \mathrm{~kg}$ and premature infants. J Interv Cardiol. 2015;28(2): | 80- | 89. https://doi.org/| 0.1 | | |/joic. 12196

4. Gross RE, Hubbard JP. Surgical ligation of a patent ductus arteriosus: A report of first successful case. JAMA 1939;1 |2:729-731. https://doi. org/l 0.100 I/jama. 1984.03340330059026.

5. Rashkind WJ, Miller WW. Transposition of the great arteries: Results of palliation by balloon atrioseptostomy in thirty-one infants. Circulation 1968; 38:453-462. https://www.ahajournals.org/doi/pdf/I 0.1 I 6 I/0 I.CIR.38.3.453 (accessed 12 March 2019).

6. Krichenko A, Benson L, Burrows P, et al. Angiographic classification of the isolated, persistently patent ductus arteriosus and implications for percutaneous catheter occlusion. The American Journal of Cardiology. 1989;63(I2):877-880. https://doi-org.ukzn.idm.oclc.org//0.1016/00029149(89)90064-7.

7. Masura J, Walsh K, Thanopoulous B, et al. Catheter closure of moderate- to large-sized patent ductus arteriosus using the new Amplatzer duct occluder: Immediate and short-term results. Journal of the American College of Cardiology. 1998;3 I (4):878-882. https://doi-org.ukzn.idm.oclc.org// 0.1016/ S0735- |097(98)000 | 3-8.

8. Waight DJ, Cao QL, Hijazi ZM. Transcatheter closure of patent ductus arteriosus using the Amplatzer duct occluder. Curr Interv Cardiol Rep. 200।;3(3):263-267. PMID: I 1485696.

9. Pass R, Hijazi Z, Hsu D, et al. Multicenter USA Amplatzer patent ductus arteriosus occlusion device trial: Initial and one-year results. ACC Current Journal Review. 2004; I3(I0):47. https://doi-org.ukzn.idm.oclc.org/ / 0.10 I 6/j. accreview.2004.08.093.

10. Butera G. Transcatheter closure of persistent ductus arteriosus with the Amplatzer duct occluder in very young symptomatic children. Heart. 2004;90(12): | 467- | 470. http://dx.doi.org/ | 0.1 | 36/hrt.2003.025 I 22.

II. Faella H. Hijazi Z. Closure of the patent ductus arteriosus with the Amplatzer PDA device: Immediate results of the international clinical trial. Catheterisation and Cardiovascular Interventions. 2000;5I(I):50-54. https://doi.org/|0.1002/1522-726X(200009)51:1\%3C50::AIDCCDII\%3E3.0.CO;2-6

12. Saliba Z, El-Rassi I, Abi-Warde M, et al. The Amplatzer duct occluder II: A new device for percutaneous ductus arteriosus closure. Journal of Interventional Cardiology. 2009;22(6):496-502. https://doi.org//0.1/11/j. |540-8| 83.2009.00504.x.

13. Masura J, Walsh K, Thanopoulous B, et al. Catheter closure of moderate- to large-sized patent ductus arteriosus using the new Amplatzer duct occluder: Immediate and short-term results. Journal of the American College of Cardiology. 1998;3। (4):878-882. https://doi-org.ukzn.idm.oclc.org// 0.1016/ S0735- 1097(98)000 I3-8.

14. Jin $M$, Liang $Y$, Wang $X$, et al. A retrospective study of I 526 cases of transcatheter occlusion of patent ductus arteriosus. Chinese Medical Journal. 2015;128(I7):2284-2289. https://www.ncbi.nlm.nih.gov/pmc/ articles/PMC4733798/pdf/CMJ-128-2284.pdf (accessed 12 March 2019).

15. El-Said H, Bratincsak A, Foerster S, et al. Safety of percutaneous patent ductus arteriosus closure: An unselected multicenter population experience. Journal of the American Heart Association. 2013;2(6):e000424. https://doi. org/ $10.1161 /$ JAHA. I 13.000424

16. Amoozgar H, Salehi S, Farhadi P, et al. Follow-up results of device occlusion of patent ductus arteriosus. Iranian Journal of Paediatrics. 2016;26(3) e362I. http://dx.doi.org/|0.58/2/ijp.362|
17. Backes C, Rivera B, Bridge J, et al. Percutaneous patent ductus arteriosus (PDA) closure during infancy: A meta-analysis. Paediatrics. 2017;139(2): e20162927. https://doi.org/l 0.I542/peds.20 I6-2927.

18. Pepeta L, Greyling A, Nxele M, et al. Patent ductus arteriosus closure using Occlutech ${ }^{\circledR}$ duct occluder, experience in Port Elizabeth, South Africa. Annals of Paediatric Cardiology. 20 17; 10(2): 131. http://www.annalspc.com/text.asp? 2017/10/2/131/205/44 (accessed I2 March 2019)

19. Baruteau A, Hascoët S, Baruteau J, et al. Transcatheter closure of patent ductus arteriosus: Past, present and future. Archives of Cardiovascular

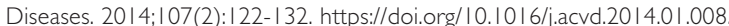

20. Pepeta L, Dippenaar A. Ductal closure using the Amplatzer duct occluder type two: Experience in Port Elizabeth hospital complex, South Africa: Cardiovascular topic. Cardiovasc J Afr. 2013;24(6):202-207. https://doi. org/l0.5830/CVJA-20I3-033

21. Galal MO, Hussain A, Arfi AM. Do we still need the surgeon to close the persistently patent arterial duct? Cardiology in the Young. 2006; I 6(6):52236. https://doi.org/10.1017/S104795/1060013/4.

22. Adams P, Chersich M, Cilliers A. Transcatheter closure of the patent ductus arteriosus at a public sector hospital in Soweto, South Africa: A review of patient outcomes over 15 years. Cardiovascular Journal of Africa. 2018; 29(4):246-25I. http://dx.doi.org/ 0.5830/CV|A-20 I 8-028.

23. Baspinar O, Sahin DA, Sulu A, et al. Transcatheter closure of patent ductus arteriosus in under $6 \mathrm{~kg}$ and premature infants. J Interv Cardiol. 2015 Apr;28(2): | 80- |89. https://doi.org/ | 0.1 | | |/joic. 12196.

24. Backes C, Kennedy K, Locke M, et al. Transcatheter occlusion of the patent ductus arteriosus in 747 Infants <6kg: Insights from the NCDR IMPACT Registry. JACC: Cardiovascular Interventions. 2017;10(17):17291737. https://doi.org/10.1016/j.jcin.2017.05.018. 